\title{
UNIFORM RESOURCE LOCATOR (URL) DETECTION SECURITY SYSTEM BASED ON ANDROID \\ Haruno Sajati ${ }^{1}$, Harliyus Agustian ${ }^{2}$, Eko Murdiansyah ${ }^{3}$ \\ Program Studi Teknik Informatika \\ Sekolah Tinggi Teknologi Adisutjipto \\ Jl. Janti Blok-R Lanud Adisutjipto Yogyakarta \\ Email : ${ }^{1}$ masjati.stta@gmail.com, ${ }^{2}$ h4rliyus@gmail.com, ${ }^{3}$ ekomurdiansyah89@gmail.com
}

\begin{abstract}
The use of the internet, which is currently increasing dramatically, certainly brings the convenience of finding information. The increase in internet usage also eventually gave rise to cybercrime crimes, one of which was by spreading a URL or fake site to steal someone's personal data. The research done is how to build an Android-based application that can detect the security of a URL. The goal is that internet users, especially social media, can avoid cybercrime crime that wants to steal personal data. Making an application uses the Regular Expression method to analyze each line of the Webpage Source Code in the URL based on 8 criteria taken from the World Wide Web Consortium (W3C). The application was then tested with 10 phishing-charged URLs and compared with Kaspersky, McAfee, and AdBlock applications. Based on the results of trials and comparisons, applications that have been made are able to detect 6 or 60\% of the 10 URLs. Kaspersky and McAfee applications can detect $70 \%$, while AdBlock only detects 3 or $30 \%$ of 10 URLs that contain phishing.
\end{abstract}

Keywords: Internet, Cybercrime, URL

\section{Latar Belakang}

Di era yang modern sekarang ini, orang-orang tidak dapat terlepas dari internet dan gadget. Seakan sudah menjadi kebutuhan pokok, kebanyakan dari orang-orang berlomba untuk memperbanyak akun sosial media mereka, dari yang hanya untuk melihat informasiinformasi terbaru yang ada, hingga yang ingin mencari kepopuleran melalui aplikasi-aplikasi seperti Facebook, Twitter, Instagram, Snapchat, dan masih banyak lagi. Peningkatan dalam penggunaan internet juga yang akhirnya melahirkan kejahatan cybercrime, salah satuya dengan cara menyebarkan URL atau situs palsu untuk mencuri data-data pribadi seseorang. Penelitian yang dikerjakan adalah membangun sebuah aplikasi berbasis Android yang mampu mendeteksi keamanan dari sebuah URL. Tujuannya agar para pengguna internet khususnya sosial media terhindar dari kejahatan cybercrime yang ingin mencuri data-data pribadi.

Sebuah penelitian [1] mengatakan bahwa dalam upaya untuk mendeteksi sebuah situs phishing bisa dilakukan dengan mengambil karakteristik sebuah web yang sah dari standar World Wide Web Consortium (W3C), dengan demikian kita dapat menemukan beberapa kriteria dari sebuah situs phishing, dan diterapkan kedalam sebuah aplikasi untuk mendeteksi sebuah situs phishing. Phishing adalah sebuah tindakan kriminal dengan tujuan mencari informasi pribadi orang lain menggunakan entitas elektronik, salah satunya adalah website, dikategorikan sebagai website phishing apabila memenuhi karakteristik phishing. Phishing dikelompokan menjadi empat kelompok yaitu, Address Bar Based Feature, Abnormal Based Feature, HTML and Javascript Based Feature dan Domain Based Feature [4]. Penelitian selanjutnya [2] juga mengatakan bahwa dalam mendeteksi sebuah situs phishing bisa dilakukan dengan metode lain yaitu Corelation Based Feature Selection dan diterapkan menggunakan Binary Logistic Regression untuk meminimalisir waktu komputasi yang dibutuhkan dalam mendeteksi situs phishing. 


\section{Metodologi Penelitian}

\subsection{Analisa Kebutuhan Sistem}

Pada pembuatan aplikasi digunakan teknologi dan metode yang digunakan untuk membangun system ini. Android adalah sistem operasi berbasis Linux untuk telepon seluler, misal smartphone atau tablet. Para pengembang dapat membuat aplikasi mereka sendiri karena Android merupakan platform yang terbuka untuk digunakan diberbagai macam smartphone [3]. Pemanfaatan Android untuk menguji coba aplikasi yang dibuat dengan memanfaatkan Regular Expression atau yang sering disebut regex adalah sebuah formula untuk pencarian pola suatu kalimat atau string. Pada level-level tertentu misal pada level rendah regex mampu mencari penggalan kata dalam string, dan bila pada level tinggi regex juga mampu mengontrol data seperti mencari, menghapus, dan merubah data string [5]. Teknik regex diterapkan pada Webpage Source Code untuk mengetahui suatu halaman website memiliki phishing. Webpage Source Code merupakan sekumpulan kode pembentuk sebuah website yang didalamnya berupa gambar dan teks yang mana akan dialamatkan menjadi sebuah URL agar dapat diakses dan ditampilkan sebagai halaman web. Bila melihat dari standar yang terdapat pada World Wide Web Consortium (W3C), maka akan ditemukan struktur kode-kode penyusun website yang sudah dinyatakan sah dan aman, namun apabila didalam Webpage Source Code tersebut terdapat beberapa kode yang asing, maka URL tersebut dinyatakan tidak sah atau tidak aman[1].

\subsection{Analisa Kebutuhan Data}

Data merupakan aspek penting yang dibutuhkan dalam proses penelitian ataupun pembuatan suatu aplikasi. Kebutuhan akan suatu data ini dapat dipenuhi dengan cara melakukan studi literatur, dan juga wawancara dengan narasumber yang berkaitan dengan apa yang akan diteliti. Beberapa kebutuhan data didapat dari berbagai jurnal penelitian untuk kebutuhan penelitian ini antara lain:

1. Kriteria penilaian URL dari W3C untuk mengecek Webpage Source Code adalah Https, Eksternal Images, Suspicious Url, Domaintag, Iframe, Suspicious Script, Popup Window [1].

2. Aturan atau rule dalam penggunaan regex untuk mencocokan Webpage Source Code dari sebuah URL dengan pattern yang telah dibuat salah satunya terdapat pada pengecekan Domaintag.

boolean has ip () \{

String url = url.getUrl();

Pattern ${ }^{-} \mathrm{p}=$ Pattern.compile(") (?: (?:25[0-5]|2[0-

4] [0-9]|[01]?

$[0-9][0-9] ?) \backslash \backslash).\{3\}(?: 25[0-5] \mid 2[0-4][0-$

9]। [01]? [0-9] [0-9]?)");

Matcher $\mathrm{m}=\mathrm{p}$.mathcer(_url);

return m.find();

\}

Pengujian aplikasi juga memerlukan sebuah data yaitu URL, dan dengan ini penulis mengumpulkan beberapa URL yang didapat dari website Phistank (https://www.phishtank.com/) dan juga URL phishing yang sengaja dibuat oleh penulis. Phistank adalah sebuah website yang mana berfungsi untuk mendeteksi phshing dalam URL dan website tersebut juga memiliki banyak URL yang sudah dinyatakan sebagai phishing. 


\subsection{Perancangan Sistem}

Use case adalah abstraksi dari interaksi antara system dan actor/user. Use case bekerja dengan cara mendeskripsikan tipe interaksi antara actor sebuah system dengan sistemnya sendiri melalui sebuah proses bagaimana sebuah sistem dipakai. Gambar 1 adalah diagram use case yang digunakan dalam pembuatan penelitian ini.

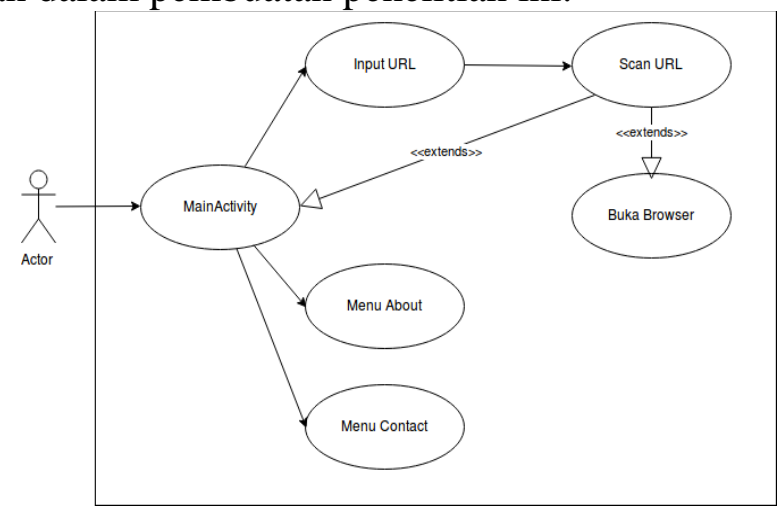

Gambar 1. Use Case Url Scanner

Class diagram, lihat gambar 2, merupakan sebuah bentuk deskripsi kelompok obyekobyek dengan property dan reaksi yang sama. Berikut adalah class diagram yang digunakan pada pembuatan aplikasi ini

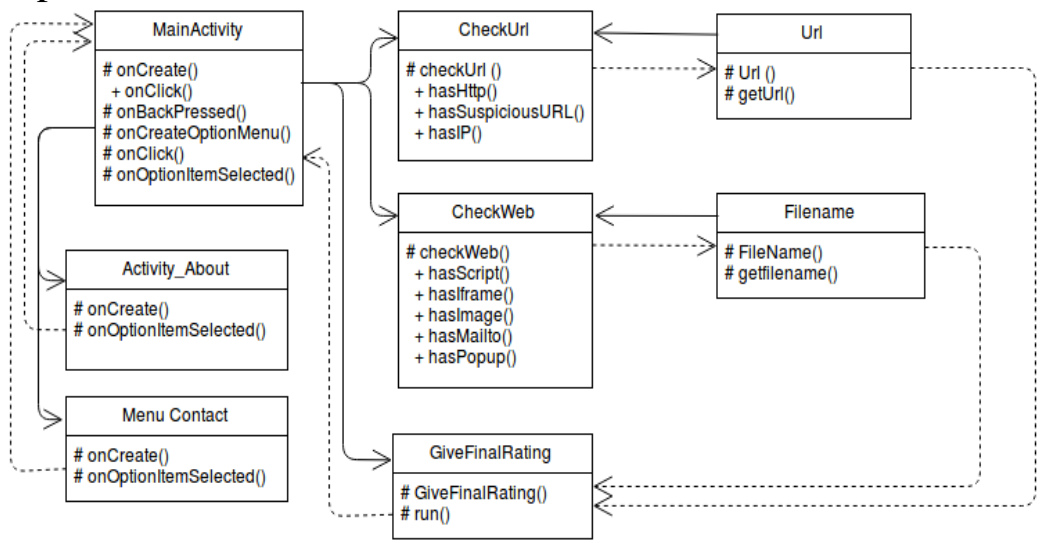

Gambar 2. Class Diagram Url Scanner

Activity diagram merupakan pendeskripsian logika prosedural dan aliran kerja dalam tahap perancangan. Activity diagram menggambarkan alur aktivitas dalam system yang sedang dirancang. Berikut adalah activity diagram yang digunakan pada pembuatan aplikasi ini dapat dilihat pada gambar 3 . 


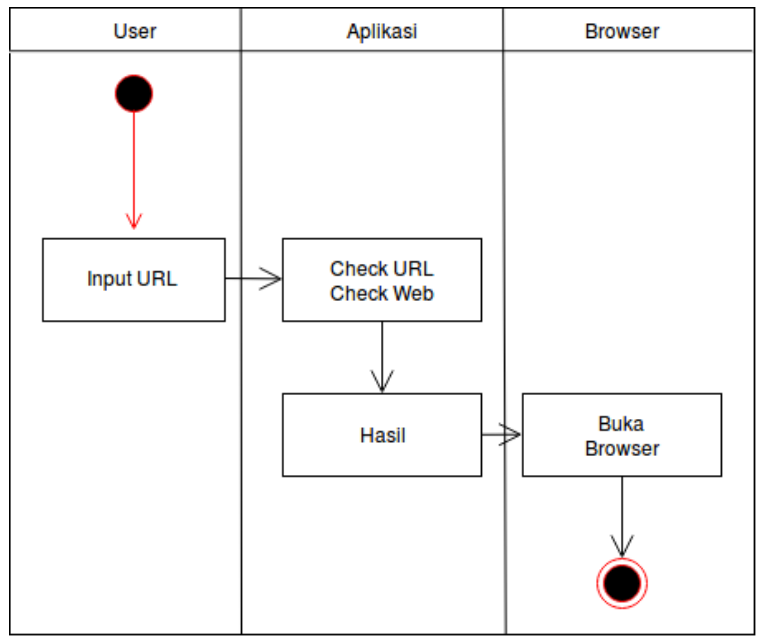

Gambar 3. Activity Diagram Url Scanner

Berikut adalah flowchart system dari pembuatan aplikasi ini dapat dilihat pada Gambar 4.
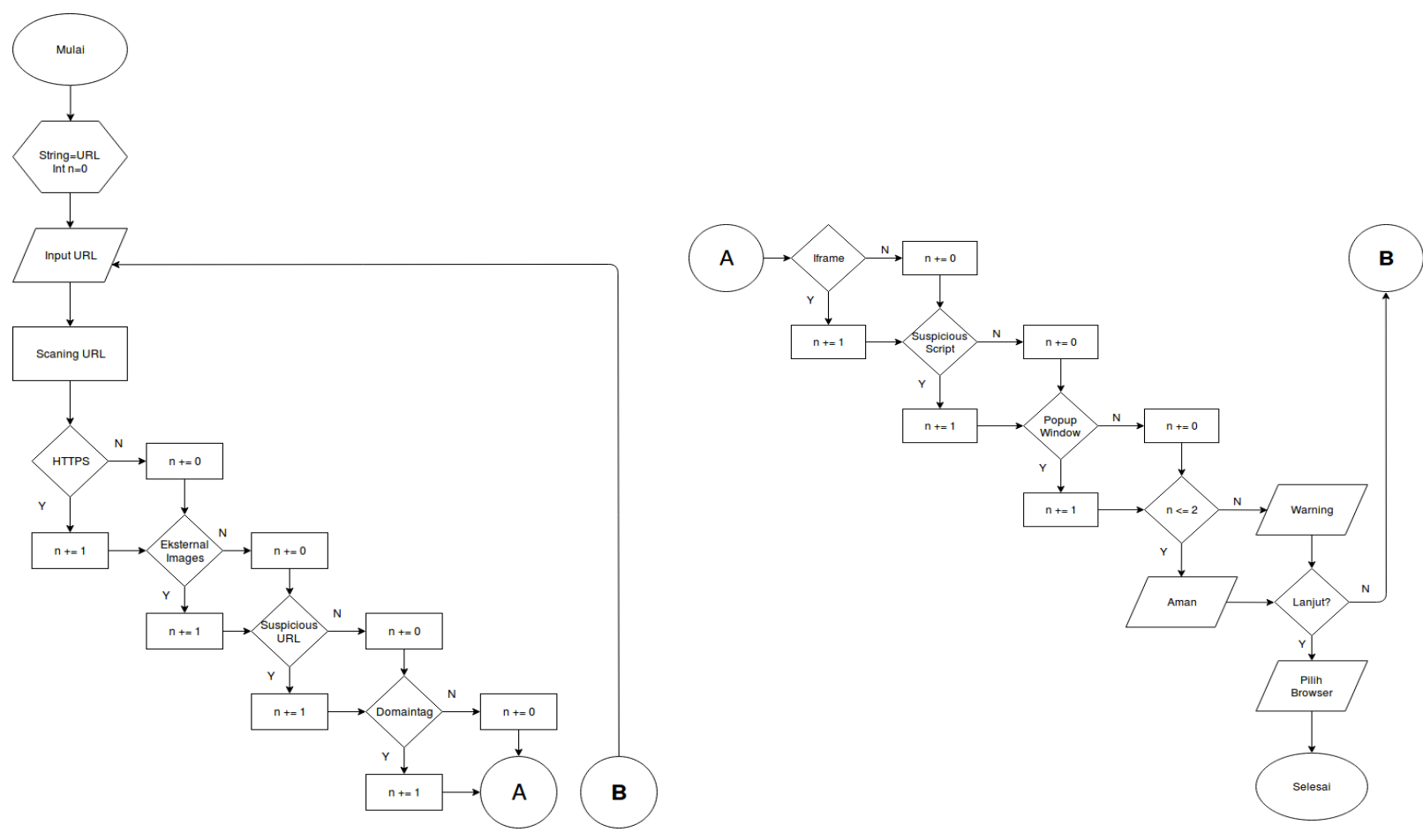

Gambar 4. Flowchart System Url Scanner

\section{Hasil dan Pembahasan}

\subsection{Pengujian}

Pengujian dilakukan dengan melakukan perbandingan kinerja antara aplikasi Url Scanner dengan Kaspersky, McAfee dan AdBlock. Tahapan pengujian menggunakan 10 URL yang mengandung phishing, lalu masing-masing URL akan diakses langsung menggunakan aplikasi Url Scanner dan mobile browser yang sudah terkonfigurasi dengan Kaspersky, McAfee, dan AdBlock. 


\subsection{Tampilan Input}

1.

Berikut adalah contoh pengujian menggunakan salah satu URL yang terdapat pada Tabel

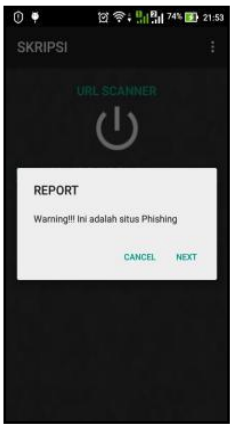

(a)

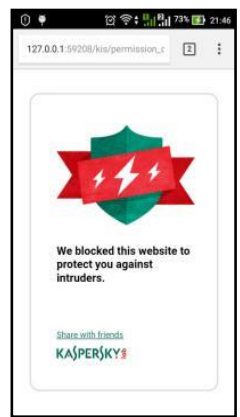

(b)

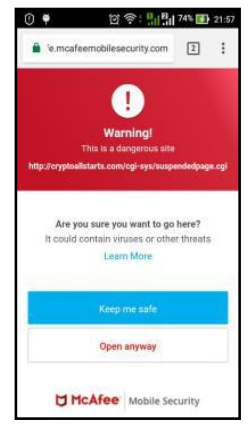

(c)

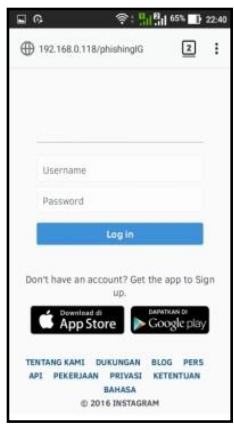

(d)

Gambar 5 Proses Input URL.

Gambar 5. (a),(b) merupakan proses input Url Scanner dari Gmail dan WhatsApp, Gambar 5.(c) merukapan proses input Kaspersky dan McAfee dari Gmail, Gambar 5.(d) merupakan proses input AdBlock dari WhatsApp)

\subsection{Tampilan Output}

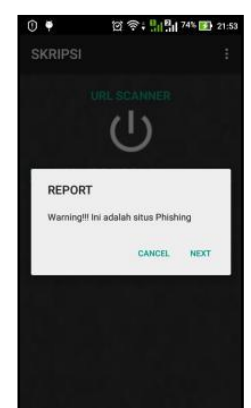

(a)

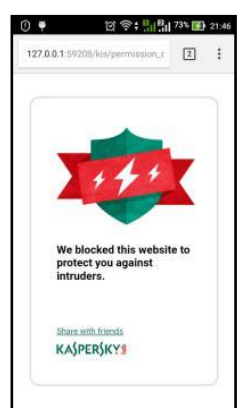

(b)

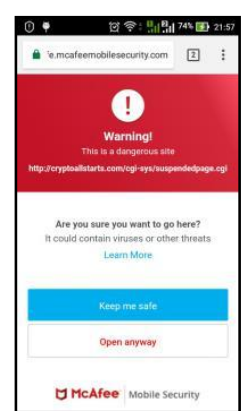

(c)

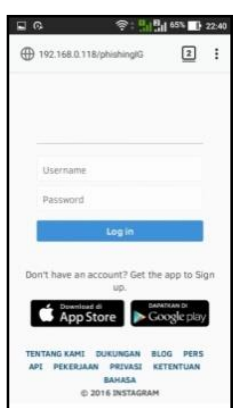

(d)

Gambar 6. Output Pengujian URL

Gambar 6. (a) output dari Url Scanner, (b) output dari Kaspersky, (c) output dari McAfee, (d) output dari AdBlock)

Output yang diperoleh kemudian dikumpulkan pada sebuah tabel dan dianalisa untuk mendapatkan total hasil dari masing-masing aplikasi dapat dilihat pada Tabel 1.

Tabel 1. Hasil Pengujian

\begin{tabular}{|l|l|l|l|}
\hline No. & URL & Aplikasi & Hasil \\
\hline 1. & http://cryptoallstarts.com/wp-includes/pomo/NAVY & Url Scanner & $\mathrm{B}$ \\
\cline { 3 - 4 } & & Kaspersky & $\mathrm{W}$ \\
\cline { 3 - 4 } & & McAfee & $\mathrm{W}$ \\
\cline { 3 - 4 } & AdBlock & $\mathrm{W}$ \\
\hline
\end{tabular}




\begin{tabular}{|c|c|c|c|}
\hline \multirow[t]{4}{*}{2.} & \multirow{4}{*}{$\begin{array}{l}\text { http://cryptoallstarts.com/wp- } \\
\text { includes/pomo/NAVY/que.php }\end{array}$} & Url Scanner & $\mathrm{B}$ \\
\hline & & Kaspersky & W \\
\hline & & McAfee & $\mathrm{W}$ \\
\hline & & AdBlock & $\mathrm{W}$ \\
\hline \multirow[t]{4}{*}{3.} & \multirow{4}{*}{$\begin{array}{l}\text { http://cryptoallstarts.com/wp- } \\
\text { includes/pomo/NAVY/full.php }\end{array}$} & Url Scanner & $\mathrm{B}$ \\
\hline & & Kaspersky & $\mathrm{W}$ \\
\hline & & McAfee & $\mathrm{W}$ \\
\hline & & AdBlock & $\mathrm{W}$ \\
\hline \multirow[t]{4}{*}{4.} & \multirow{4}{*}{$\begin{array}{l}\text { http://www.seanfeitoakes.com/wp/ } \\
\text { www.loginalibaba.com/alibaba/alibaba/ } \\
\text { login.alibaba.com.php?email=pro-ricky@ outook.com } \\
\% 5 \mathrm{Cr} \% 5 \mathrm{Cn}\end{array}$} & Url Scanner & $\mathrm{W}$ \\
\hline & & Kaspersky & $\mathrm{W}$ \\
\hline & & McAfee & $\mathrm{W}$ \\
\hline & & AdBlock & $\mathrm{B}$ \\
\hline \multirow[t]{4}{*}{5.} & \multirow[t]{4}{*}{ http://192.168.0.118/phishingIG/ } & Url Scanner & $\mathrm{W}$ \\
\hline & & Kaspersky & $\mathrm{B}$ \\
\hline & & McAfee & $\mathrm{B}$ \\
\hline & & AdBlock & $\mathrm{B}$ \\
\hline \multirow[t]{4}{*}{6.} & \multirow{4}{*}{$\begin{array}{l}\text { http://webdicomviewer.com/ } \\
\text { 705646f811 ef8210c0fc91afbfd6eb45/ }\end{array}$} & Url Scanner & $\mathrm{W}$ \\
\hline & & Kaspersky & $\mathrm{B}$ \\
\hline & & McAfee & $\mathrm{W}$ \\
\hline & & AdBlock & $\mathrm{B}$ \\
\hline \multirow[t]{4}{*}{7.} & \multirow[t]{4}{*}{ http://192.168.0.118/facebook/ } & Url Scanner & $\mathrm{W}$ \\
\hline & & Kaspersky & $\mathrm{B}$ \\
\hline & & McAfee & $\mathrm{B}$ \\
\hline & & AdBlock & $\mathrm{B}$ \\
\hline \multirow[t]{4}{*}{8.} & \multirow[t]{4}{*}{ http://utm.io/ub8Jo } & Url Scanner & $\mathrm{B}$ \\
\hline & & Kaspersky & $\mathrm{W}$ \\
\hline & & McAfee & $\mathrm{B}$ \\
\hline & & AdBlock & $\mathrm{B}$ \\
\hline \multirow[t]{4}{*}{9.} & \multirow{4}{*}{$\begin{array}{l}\text { http://smartpropertiesmy.com/wealt/docusign-lock/ } \\
\text { index.php }\end{array}$} & Url Scanner & $\mathrm{W}$ \\
\hline & & Kaspersky & $\mathrm{W}$ \\
\hline & & McAfee & $\mathrm{W}$ \\
\hline & & AdBlock & $\mathrm{B}$ \\
\hline \multirow[t]{4}{*}{10.} & \multirow[t]{4}{*}{ http://larayasociados.com.mx/atz/l0ginn } & Url Scanner & $\mathrm{W}$ \\
\hline & & Kaspersky & $\mathrm{W}$ \\
\hline & & McAfee & $\mathrm{W}$ \\
\hline & & AdBlock & $\mathrm{B}$ \\
\hline
\end{tabular}

Keterangan: Warning (W), Bukan Phishing (B).

\subsection{Analisa Hasil Pengujian}

Tabel 2 menunjukkan hasil pengujian dalam bentuk persentase yang telah didapatkan dari hasil perhitungan berdasarkan kriteria penilaian Warning (W), Bukan Phishing (B). Dari tabel diatas terlihat bahwa aplikasi Kaspersky dan McAfee memiliki persentase yang lebih besar terhadap sepuluh URL yang mengandung phishing dan konten ilegal dengan jumlah 70\%, kemudian aplikasi Url Scanner memiliki jumlah persentase 60\% dari uji coba menggunakan sepuluh URL phishing. AdBlock memiliki persentase yang jauh lebih kecil terhadap URL yang mengandung phishing dan konten ilegal yaitu 30\%. 
Tabel 2. Analisa Hasil Pengujian

\begin{tabular}{|l|l|l|l|}
\hline \multirow{2}{*}{ No. } & \multirow{2}{*}{ Aplikasi } & Kriteria \\
\cline { 3 - 4 } & & W & B \\
\hline 1. & Url Scanner & $60 \%$ & $40 \%$ \\
\hline 2. & Kaspersky & $70 \%$ & $30 \%$ \\
\hline 3. & McAfee & $70 \%$ & $30 \%$ \\
\hline 4. & AdBlock & $30 \%$ & $70 \%$ \\
\hline
\end{tabular}

\section{Kesimpulan} bahwa:

Berdasarkan hasil pengujian yang dilakukan pada penelitianini dapat disimpulkan

1. Pengujian yang mengacu pada pengecekan Webpage Source Code dari sepuluh URL menggunakan metode Regular Expression, dapat disimpulkan bahwa metode ini cukup efektif untuk digunakan dalam mendeteksi muatan phishing dan konten ilegal didalam URL.

2. Aplikasi Url Scanner mampu mendeteksi $60 \%$ dari sepuluh URL yang mengandung phishing. Kaspersky dan McAfee yang mendapat total hasil $70 \%$, yang berarti aplikasi Url Scanner cukup bagus digunakan untuk mendeteksi URL yang mengandung phishing dan konten ilegal, sedangkan pada AdBlock mendapatkan total hasil 30\% dan berarti aplikasi ini kurang cocok digunakan untuk mendeteksi phishing didalam URL.

\section{Daftar Pustaka}

[1] Alkhozae, M. G., \& Batarfi, O. A. (2011). Phishing websites detection based on phishing characteristics in the webpage source code. International Journal of Information and Communication Technology Research, 1(6).

[2] Mohammad, R. M., Thabtah, F., \& McCluskey, L. (2014). Intelligent rule-based phishing websites classification. IET Information Security, 8(3), 153-160.

[3] Horton, J. (2015). Android Programming for Beginners. Packt Publishing Ltd.

[4] Kuchling, A. M. (2014). Regular Expression HOWTO. Regular Expression HOWTOPython, 2(10).

[5] Sudaryanto, S. (2018, November). Implementation Port Security for Security Systems Network at the Computing Laboratory of Adisutjipto College of Technology. In Conference SENATIK STT Adisutjipto Yogyakarta (Vol. 4).

[6] Setiawan, Y., Sajati, H., \& Sudibya, B. (2013). Perancangan Keamanan Sistem Menggunakan Algoritma Honeypot pada Aplikasi Krs Online (Studi Kasus: Sekolah Tinggi Teknologi Adisutjipto). Compiler, 2(2).

[7] Zonggonau, K., \& Sajati, H. (2015). Membangun Sistem Keamanan ARP Spoofing Memanfaatkan Arpwatch dan Addons Firefox. Compiler, 4(1).

[8] Hamka, C. A., Sajati, H., \& Indrianingsih, Y. (2014). Sistem Keamanan Jail Bash Untuk Mengamankan Akun Legal Dari Kejahatan Internet MenggunakanThc-hydra. Compiler, 3(1). 
[9] Suhendar, A. S. S., Sajati, H., \& Astuti, Y. (2013). Perancangan Algoritma Anggi (Aa) dengan Memanfaatkan Diffie-hellman dan Ronald Rivest(Rc4) untuk Membangun Sistem Keamanan Berbasis Port Knocking. Compiler,2(2).

[10] Widodo, A. P., Sarwoko, E. A., Suharto, E., \& Siahaan, J. F. O. (2016). Pengamanan Data Foto Pada Perangkat Os Android Menggunakan Teknikkriptografi Hill Cipher. JISKA (Jurnal Informatika Sunan Kalijaga), 1(2).

[11] Rifa'i, A. F. (2016). Sistem Pendeteksi Dan Monitoring Kebocoran Gas(Liquefied Petrolum Gas) Berbasis Internet Of Things. 